\title{
Trend Analysis of Generalized Hypergeometric Functions
}

\author{
Pramod Joshi \\ Department of Mathematics \\ L. S. M. Government P G College \\ Pithoragarh, India
}

\author{
Prof. H. S. Dhami \\ Head, Department of Mathematics \\ Kumaun University, \\ S. S. J. Campus Almora, India
}

\begin{abstract}
An innovative attempt to analyze the trends of different generalized hypergeometric functions of the form ${ }_{p} F_{q} \quad \boldsymbol{a} ; \boldsymbol{b} ; \boldsymbol{x}$ has been made in this research paper by using matlab and the nature of generalized hypergeometric functions like $4 \mathrm{~F} 3(1,2,3,4 ; 3,4,5 ; \mathrm{x})$ and $8 \mathrm{~F} 4$ $(1,2,3,4,5,6,7,8 ; 3,5,7,9 ; \mathrm{x})$ has been demonstrated. Comparison work of different generalized hypergeometric functions has been also undertaken.
\end{abstract}

\section{Keywords}

Generalized hypergeometric function, special function, matlab.

\section{INTRODUCTION}

The term "trend analysis" refers to the concept of collecting information and attempting to spot a pattern, or trend, in the information. In some fields of study, the term "trend analysis" has more formally-defined meaning. Trend analysis often refers to the science of studying changes in social patterns, including fashion, technology and the consumer behavior. Modern society is increasingly reliant on our capability to automatically detect patterns in vast masses of data. This is affecting not only the way we do business and run our industries, but also is changing the very nature of the scientific method. Every science now has an eversion (computational biology, computational chemistry, etc) and in many cases this involves automatisation of both the production and the analysis of experimental data. The use of computer simulations increases our reliance on automatic analysis of data even further this process is accelerating.

The distinct scientific communities that are working on various aspects of automatic analysis of data include Combinatorial Pattern Matching, Data Mining, Computational Statistics, Network Analysis, Text Mining, Image Processing, Syntactical Pattern Recognition, Machine Learning, Statistical Pattern Recognition, Computer Vision, and many others. We ca see the works on generalized Hypergeometric Functions of Dwork B. (1990) and Yoshida Masaaki (1997). Watanabe Y et al(1998) deals with a fast structural matching and its application to pattern analysis of 2-D electrophoresis images. We can see the work of Desmond J. Higham et al (2005) on MATLAB. Another important work of Rumshisky et al (2006) deals with inducing sense-discriminating context patterns from sense-tagged corpora. We can also quote the work of Bevel Tom et al (2008) on bloodstain pattern analysis with an introduction to crime scene reconstruction and of Hui Wang et al (2009) for high-definition metrology based spatial variation pattern analysis for the dynamic pattern analysis framework to the analysis of spatial-temporal crime relationships. The important work on MATLAB of Stormy
Attaway (2009).We can see the work on generalised hypergeometric function is Askey, R. A. (2010), Daalhuis, Adri B. Olde (2010),

\section{DATABASE 1 OF GENERALIZED HYPERGEOMATRIC FUNCTION 4F3 $(1,2$,} 3, 4; 3, 4, 5; X)

We have created the databases from generalized hypergeometric function $4 \mathrm{~F} 3(1,2,3,4 ; 3,4,5 ; \mathrm{x})$ and have plotted the graph between real and imaginary part of $4 \mathrm{~F} 3(1,2,3,4 ; 3,4,5 ; \mathrm{x})$ with the help of MATLAB, then interpreted the pattern of generalized hypergeometric function $4 \mathrm{~F} 3(1,2,3,4 ; 3,4,5 ; \mathrm{x})$ in different range of $x$.

\begin{tabular}{|c|c|c|c|c|c|}
\hline $\mathbf{X}$ & \multicolumn{5}{|c|}{${ }_{\mathbf{4}} \mathbf{F}_{\mathbf{3}}(\mathbf{1}, \mathbf{2 , 3} \mathbf{3} \mathbf{3} \mathbf{3 , 4 , 5} \mathbf{x})$} \\
\hline 2 to 10 & $1-$ & $-0.52598-$ & $-0.59478-$ & $-0.52153-$ & $-0.44557-$ \\
(step 2) & $2.3562 \mathrm{i}$ & $1.3254 \mathrm{i}$ & $0.72722 \mathrm{i}$ & $0.45099 \mathrm{i}$ & $0.30536 \mathrm{i}$ \\
\hline 2 to 20 & $-0.38319-$ & $-0.33366-$ & $-0.29419-$ & $-0.26232-$ & $-0.23622-$ \\
(step 2) & $0.21998 \mathrm{i}$ & $0.16585 \mathrm{i}$ & $0.12943 \mathrm{i}$ & $0.10379 \mathrm{i}$ & $0.085059 \mathrm{i}$ \\
\hline 22to 30 & $-0.21453-$ & $-0.19628-$ & $-0.18073-$ & $-0.16735-$ & $-0.15573-$ \\
(step 2) & $0.070971 \mathrm{i}$ & $0.060109 \mathrm{i}$ & $0.051561 \mathrm{i}$ & $0.044712 \mathrm{i}$ & $0.039142 \mathrm{i}$ \\
\hline 32 to 40 & $-0.14555-$ & $-0.13657-$ & $-0.1286-$ & $-0.12147-$ & $-0.11506-$ \\
(step 2) & $0.034551 \mathrm{i}$ & $0.030722 \mathrm{i}$ & $0.027495 \mathrm{i}$ & $0.024751 \mathrm{i}$ & $0.022399 \mathrm{i}$ \\
\hline 42 to 50 & $-0.10927-$ & $-0.10402-$ & $-0.099233-$ & $-0.094855-$ & $-0.090837-$ \\
(step 2) & $0.020366 \mathrm{i}$ & $0.018598 \mathrm{i}$ & $0.01705 \mathrm{i}$ & $0.015688 \mathrm{i}$ & $0.014482 \mathrm{i}$ \\
\hline
\end{tabular}

Database 1.1

\begin{tabular}{|c|c|c|c|c|c|}
\hline $\mathbf{X}$ & \multicolumn{5}{|c|}{$4 \mathrm{~F} 3(1,2,3,4 ; 3,4,5 ; x)$} \\
\hline $\begin{array}{l}52 \text { to } 60 \\
\text { (step } 2)\end{array}$ & $\begin{array}{r}-0.08713 \\
0.01341 \mathrm{i}\end{array}$ & $\begin{array}{c}-0.08371- \\
0.01245 \mathrm{i}\end{array}$ & $\begin{array}{c}-0.08054- \\
0.01159 \mathrm{i}\end{array}$ & $\begin{array}{c}-0.07760- \\
0.01082 \mathrm{i}\end{array}$ & $\begin{array}{r}-0.07486 \\
0.01012 \mathrm{i}\end{array}$ \\
\hline $\begin{array}{l}\text { 62to } 70 \\
\text { (step 2) }\end{array}$ & $\begin{array}{l}-0.07230 \\
0.009493 i\end{array}$ & $\begin{array}{c}-0.06991- \\
0.008918 \mathrm{i}\end{array}$ & $\begin{array}{l}-0.06766- \\
0.008394 \mathrm{i}\end{array}$ & $\begin{array}{l}-0.06556- \\
0.007914 \mathrm{i}\end{array}$ & $\begin{array}{l}-0.06357 \\
0.007475 i\end{array}$ \\
\hline $\begin{array}{l}\text { 72to } 80 \\
\text { (step 2) }\end{array}$ & $\begin{array}{l}-0.06171 \\
0.007071 \mathrm{i}\end{array}$ & $\begin{array}{l}-0.05994- \\
0.006699 i\end{array}$ & $\begin{array}{l}-0.05827- \\
0.006356 \mathrm{i}\end{array}$ & $\begin{array}{l}-0.05669- \\
0.006038 \mathrm{i}\end{array}$ & $\begin{array}{c}-0.0552- \\
0.005744 \mathrm{i}\end{array}$ \\
\hline $\begin{array}{l}82 \text { to } 90 \\
(\text { step } 2)\end{array}$ & $\begin{array}{l}-0.05377 \\
0.005470 \mathrm{i}\end{array}$ & $\begin{array}{l}-0.05242- \\
0.005216 \mathrm{i}\end{array}$ & $\begin{array}{l}-0.05113- \\
0.004979 \mathrm{i}\end{array}$ & $\begin{array}{c}-0.04991- \\
0.004758 \mathrm{i}\end{array}$ & $\begin{array}{l}-0.04874 \\
0.004551 \mathrm{i}\end{array}$ \\
\hline $\begin{array}{c}92 \text { to } 100 \\
\text { (step 2) }\end{array}$ & $\begin{array}{l}-0.04762 \\
0.004357 \mathrm{i}\end{array}$ & $\begin{array}{l}-0.04655- \\
0.004176 \mathrm{i}\end{array}$ & $\begin{array}{c}-0.04553- \\
0.004005 \mathrm{i}\end{array}$ & $\begin{array}{c}-0.04455- \\
0.003845 \mathrm{i}\end{array}$ & $\begin{array}{l}-0.04361 \\
0.003694 \mathrm{i}\end{array}$ \\
\hline
\end{tabular}

Database 1.2 


\section{MATLAB PROGRAM FOR PLOTTING GENERALIZED HYPERGEOMETRIC FUNCTION, 4F3 $(1,2,3,4 ; 3,4,5 ; \mathrm{X})$}

MATLAB program for fig 1.1:

$>\mathrm{x}=[2: 2: 10 ; 12: 2: 20 ; 22: 2: 30 ; 32: 2: 40 ; 42: 2: 50]$;

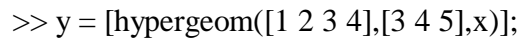

> $\operatorname{plot}(\mathrm{y})$;

MATLAB program for fig 1.2:

> $\mathrm{x}=[52: 2: 60 ; 62: 2: 70 ; 72: 2: 80 ; 82: 2: 90 ; 92: 2: 100]$;

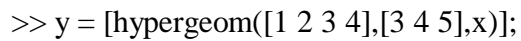

>> plot(y);

Pattern of Generalized Hypergeometric Function ${ }_{4} F_{3}(1,2,3,4 ; 3,4,5 ; x)$
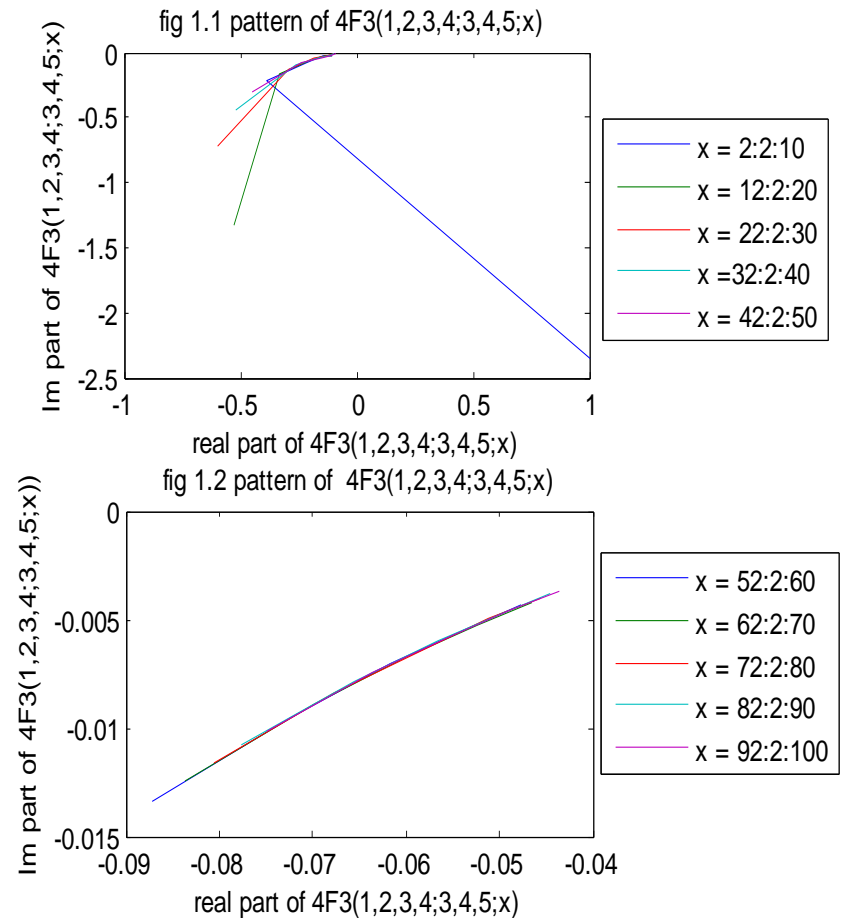

\section{INTERPRETATION}

The databases 1.1 and 1.2 having values in complex numbers, indicate that when we move to higher hypergeometric function like ${ }_{4} \mathrm{~F}_{3}(1,2,3,4 ; 3,4,5 ; \mathrm{x})$ the data turns into complex number form. It can be seen from figure 1.1 and figure 1.2 when the range of $\mathrm{x}$ increases the data converse quickly.

\section{Database 2 of Generalized Hypergeometric} Function ${ }_{8} \mathbf{F}_{4}(1,2,3,4,5,6,7,8 ; 3,5,7,9 ; x)$

We have created two databases from generalized hypergeometric function $8 \mathrm{~F} 4(1,2,3,4,5,6,7,8 ; 3,5,7,9 ; \mathrm{x})$ and have plotted the graph between real and imaginary part of $8 \mathrm{~F} 4(1,2,3,4,5,6$, $7,8 ; 3,5,7,9 ; x)$ with the help of MATLAB which have helped us in interpretation the pattern of generalized hypergeomatric function ${ }_{8} \mathrm{~F}_{4}(1,2,3,4,5,6,7,8 ; 3,5,7,9 ; \mathrm{x})$ in different ranges of $x$.

\section{Database 2.1}

\begin{tabular}{|c|c|c|c|c|c|}
\hline $\mathbf{X}$ & \multicolumn{5}{|c|}{${ }_{8} F_{4}(1,2,3,4,5,6,7,8 ; 3,5,7,9 ; x)$} \\
\hline $\begin{array}{l}2 \text { to } 10 \\
\text { (step 2) }\end{array}$ & \begin{tabular}{|c|}
-0.0014851 \\
$-1.2813 \mathrm{e}-$ \\
$005 \mathrm{i}$
\end{tabular} & $\begin{array}{c}-0.0014296 \\
-1.1884 \mathrm{e}- \\
005 \mathrm{i}\end{array}$ & $\begin{array}{c}-0.001378 \\
1.1053 \mathrm{e}- \\
005 \mathrm{i}\end{array}$ & $\begin{array}{c}-0.00133- \\
1.0307 \mathrm{e}- \\
005 \mathrm{i}\end{array}$ & \begin{tabular}{|c|}
-0.0012853 \\
$-9.6332 \mathrm{e}-$ \\
$006 \mathrm{i}$
\end{tabular} \\
\hline $\begin{array}{l}12 \text { to } 20 \\
(\text { step } 2)\end{array}$ & $\mid \begin{array}{c}-0.0012434 \\
-9.0236 \mathrm{e}- \\
006 \mathrm{i}\end{array}$ & $\begin{array}{c}-0.0012042 \\
-8.4701 \mathrm{e}- \\
006 \mathrm{i}\end{array}$ & $\begin{array}{c}-0.0011674 \\
-7.966 \mathrm{e}- \\
006 \mathrm{i}\end{array}$ & $\begin{array}{c}-0.0011328 \\
-7.5056 \mathrm{e}- \\
006 \mathrm{i}\end{array}$ & $\begin{array}{c}-0.0011001 \\
-7.084 \mathrm{e}- \\
006 \mathrm{i}\end{array}$ \\
\hline $\begin{array}{l}\text { 22to 30 } \\
\text { (step 2) }\end{array}$ & $\mid \begin{array}{c}-0.0010693 \\
-6.6969 \mathrm{e}- \\
006 \mathrm{i}\end{array}$ & $\begin{array}{c}-0.0010402 \\
-6.3407 \mathrm{e}- \\
006 \mathrm{i}\end{array}$ & $\begin{array}{c}-0.0010126 \\
-6.0122 \mathrm{e}- \\
006 \mathrm{i}\end{array}$ & $\begin{array}{c}- \\
0.0009864 \\
2-5.7086 \mathrm{e}- \\
006 \mathrm{i}\end{array}$ & $\mid \begin{array}{c}0.0009615 \\
7-5.4274 \mathrm{e}- \\
006 \mathrm{i}\end{array}$ \\
\hline $\begin{array}{l}32 \text { to } 40 \\
\text { (step 2) }\end{array}$ & \begin{tabular}{|c|}
- \\
0.0009379 \\
$4-5.1665 \mathrm{e}-$ \\
$006 \mathrm{i}$
\end{tabular} & $\begin{array}{c}- \\
0.0009154 \\
4-4.924 \mathrm{e}- \\
006 \mathrm{i}\end{array}$ & $\begin{array}{c}-0.000894- \\
4.6981 \mathrm{e}- \\
006 \mathrm{i}\end{array}$ & $\begin{array}{c}- \\
0.0008735 \\
3-4.4874 \mathrm{e}- \\
006 \mathrm{i}\end{array}$ & \begin{tabular}{|c|}
- \\
0.0008539 \\
$9-4.2906 \mathrm{e}-$ \\
$006 \mathrm{i}$
\end{tabular} \\
\hline $\begin{array}{l}42 \text { to } 50 \\
\text { (step 2) }\end{array}$ & \begin{tabular}{|c|}
- \\
0.0008352 \\
$9-4.1065 \mathrm{e}-$ \\
$006 \mathrm{i}$
\end{tabular} & $\begin{array}{c}-0.0008174 \\
-3.934 \mathrm{e}- \\
006 \mathrm{i}\end{array}$ & $\begin{array}{c}- \\
0.00080026 \\
-3.7721 \mathrm{e}- \\
006 \mathrm{i}\end{array}$ & $\begin{array}{c}- \\
0.0007838 \\
2-3.62 \mathrm{e}- \\
006 \mathrm{i}\end{array}$ & \begin{tabular}{|c|}
- \\
0.0007680 \\
$4-3.4769 \mathrm{e}-$ \\
$006 \mathrm{i}$
\end{tabular} \\
\hline
\end{tabular}

\begin{tabular}{|c|c|c|c|c|c|}
\hline $\mathbf{X}$ & \multicolumn{5}{|c|}{${ }_{8} \mathbf{F}_{4}(1,2,3,4,5,6,7,8 ; 3,5,7,9 ; x)$} \\
\hline $\begin{array}{l}2 \text { to } 10 \\
\text { (step } 2 \text { ) }\end{array}$ & $1-2.3562 \mathrm{i}$ & $\begin{array}{c}-0.52598- \\
1.3254 \mathrm{i}\end{array}$ & $\begin{array}{c}-0.59478- \\
0.72722 \mathrm{i}\end{array}$ & $\begin{array}{c}-0.52153- \\
0.45099 \mathrm{i}\end{array}$ & $\begin{array}{c}-0.44557- \\
0.30536 \mathrm{i}\end{array}$ \\
\hline $\begin{array}{l}12 \text { to } 20 \\
\text { (step 2) }\end{array}$ & $\begin{array}{c}-0.38319- \\
0.21998 \mathrm{i}\end{array}$ & $\begin{array}{c}-0.33366- \\
0.16585 \mathrm{i}\end{array}$ & $\begin{array}{c}-0.29419- \\
0.12943 \mathrm{i}\end{array}$ & $\begin{array}{c}-0.26232- \\
0.10379 \mathrm{i}\end{array}$ & $\begin{array}{l}-0.23622- \\
0.085059 \mathrm{i}\end{array}$ \\
\hline $\begin{array}{l}22 \text { to } 30 \\
\text { (step 2) }\end{array}$ & $\begin{array}{l}-0.21453- \\
0.070971 \mathrm{i}\end{array}$ & $\begin{array}{l}-0.19628- \\
0.060109 \mathrm{i}\end{array}$ & $\begin{array}{l}-0.18073- \\
0.051561 \mathrm{i}\end{array}$ & $\begin{array}{l}-0.16735- \\
0.044712 i\end{array}$ & $\begin{array}{l}-0.15573- \\
0.039142 \mathrm{i}\end{array}$ \\
\hline $\begin{array}{l}32 \text { to } 40 \\
\text { (step } 2 \text { ) }\end{array}$ & $\begin{array}{l}-0.14555- \\
0.034551 \mathrm{i}\end{array}$ & $\begin{array}{l}-0.13657- \\
0.030722 \mathrm{i}\end{array}$ & $\begin{array}{l}-0.1286- \\
0.027495 i\end{array}$ & $\begin{array}{l}-0.12147- \\
0.024751 \mathrm{i}\end{array}$ & $\begin{array}{l}-0.11506- \\
0.022399 \mathrm{i}\end{array}$ \\
\hline $\begin{array}{l}42 \text { to } 50 \\
\text { (step 2) }\end{array}$ & $\begin{array}{l}-0.10927- \\
0.020366 \mathrm{i}\end{array}$ & $\begin{array}{r}-0.10402- \\
0.018598 \mathrm{i}\end{array}$ & $\begin{array}{r}-0.099233 \\
0.01705 \mathrm{i}\end{array}$ & $\begin{array}{c}-0.09485- \\
0.015688 \mathrm{i}\end{array}$ & $\begin{array}{c}-0.090837- \\
0.014482 \mathrm{i}\end{array}$ \\
\hline
\end{tabular}

Database 2.2 


\section{MATLAB Program for Plotting} Generalized Hypergeometric Function, 8F4 (1, 2, 3, 4, 5, 6, 7, 8; 3, 5, 7, 9; x) For Pattern Identification

MATLAB program for fig 2.1:

$>\mathrm{x}=[2: 2: 10 ; 12: 2: 20 ; 22: 2: 30 ; 32: 2: 40 ; 42: 2: 50]$;

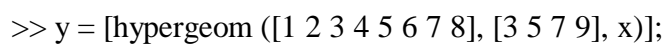

> $\operatorname{plot}(\mathrm{y})$;

MATLAB program for fig 2.2:

> $\mathrm{x}=[52: 2: 60 ; 62: 2: 70 ; 72: 2: 80 ; 82: 2: 90 ; 92: 2: 100]$;

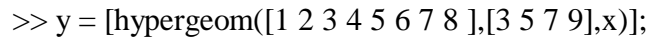

>> plot(y);

7. Pattern of Generalized Hypergeomatric Function 8F4 $(1,2,3,4,5,6,7,8 ; 3,5,7,9 ; x)$
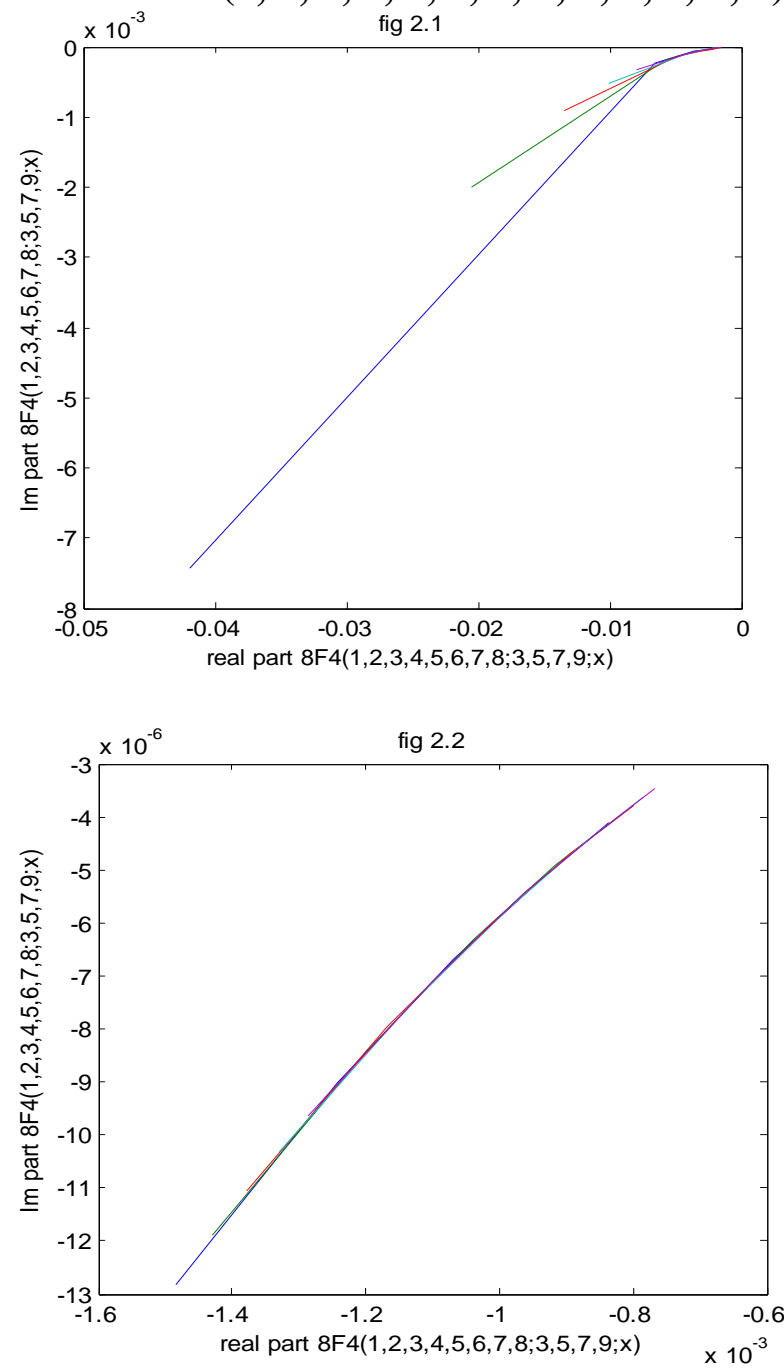

\section{INTERPRETATION}

We observe that all values in databases 2.1 and 2.2 are in complex numbers which replicate that when we move to higher hypergeometric function like $8 \mathrm{~F} 4(1,2,3,4,5,6,7,8 ; 3,5,7,9$; $\mathrm{x})$ the data turns into complex number form. It is evident from figures 2.1 and 2.2, where with the increase in the range of $\mathrm{x}$, it can be seen that the data converse quickly.

\section{Matlab Program for Pattern Identification of Special Function in Different Range}

$$
\begin{aligned}
& \text { > fplot(@(x)x.*hypergeom([1/2 1/2],3/2,x.^2),[-0.1 0.1]); } \\
& \text { > fplot(@(x) x.*hypergeom([1/2 1/2],3/2,x.^2),[-0.2 0.2]); } \\
& \text { > fplot(@(x) x.*hypergeom([1/2 1/2],3/2,x.^2),[-0.3 0.3]); } \\
& \text { >>fplot(@(x)x.*hypergeom([1/2 1/2],3/2,x.^2),[-0.4 0.4]); } \\
& \text { > fplot(@(x) x.*hypergeom([1/2 1/2],3/2,x.^2),[-0.5 0.5]); } \\
& \text { > fplot(@(x)x.*hypergeom([1/2 1/2],3/2,x.^2),[-0.6 0.6]); } \\
& \text { > fplot(@(x)x.*hypergeom([1/2 1/2],3/2,x.^2),[-0.7 0.7]); } \\
& \text { > fplot(@(x) x.*hypergeom([1/2 1/2],3/2,x.^2),[-0.8 0.8]); } \\
& \text { > fplot(@(x) x.*hypergeom([1/2 1/2],3/2,x.^2),[-0.9 0.9]); } \\
& \text { > fplot(@(x) x.*hypergeom([1/2 1/2],3/2,x.^2),[- } 11]) \text {; } \\
& \text { > fplot(@(x) x.*hypergeom([1/2 1/2],3/2,x.^2),[-1.1 1.1]); } \\
& \text { > fplot(@(x) x.*hypergeom([1/2 1/2],3/2,x.^2),[-1.2 1.2]); }
\end{aligned}
$$

> fplot(@(x)x.*hypergeom([1/2 1/2],3/2,x.^2),[-10 10]);

> fplot(@(x)x.*hypergeom([1/2 1/2],3/2,x.^2),[-15 15]);

>>fplot(@(x) x.*hypergeom([1/2 1/2],3/2,x.^2),[-100 100]);

> fplot(@(x) x.*hypergeom([1/2 1/2],3/2,x.^2),[-1000 1000]);

> fplot(@(x)x.*hypergeom([1/2 1/2],3/2,x.^2),[-10000 10000]);

>> fplot(@(x) x.*hypergeom([1/2 1/2],3/2,x.^2),[-100000 100000]);

10. Trend Analysis of the Special Function $x_{2} F_{1}\left(1 / 2,1 / 2 ; 3 / 2 ; x^{2}\right)$ in Different ranges

We have taken the function $\mathrm{x} 2 \mathrm{~F} 1(1 / 2,1 / 2 ; 3 / 2 ; \mathrm{x} 2)$ and have plotted it in different ranges of values of $\mathrm{x}$ with the help of MATLAB . It has paved the way of analyzing the trend of the function $\mathrm{x} 2 \mathrm{~F} 1(1 / 2,1 / 2 ; 3 / 2 ; \mathrm{x} 2)$ in different ranges of values of $\mathrm{x}$. 
fig 3.1
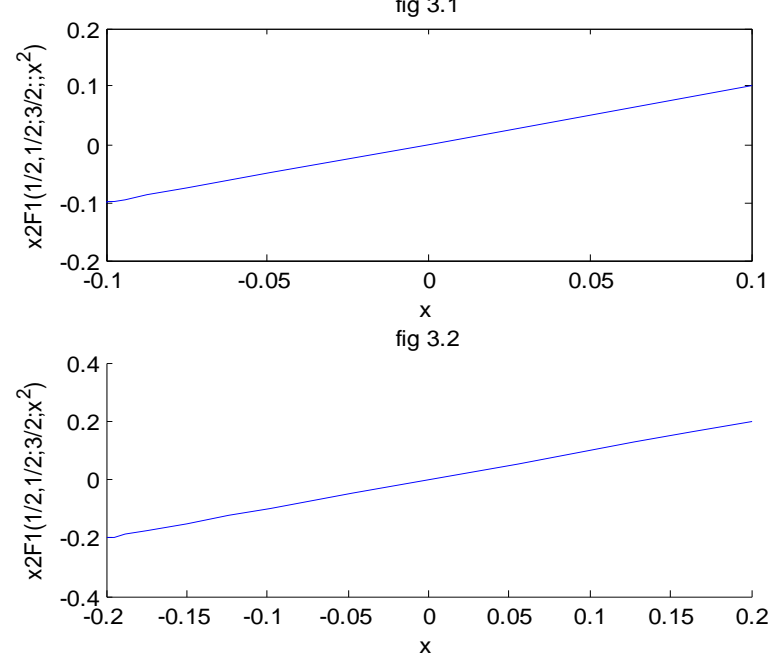

fig 3.3
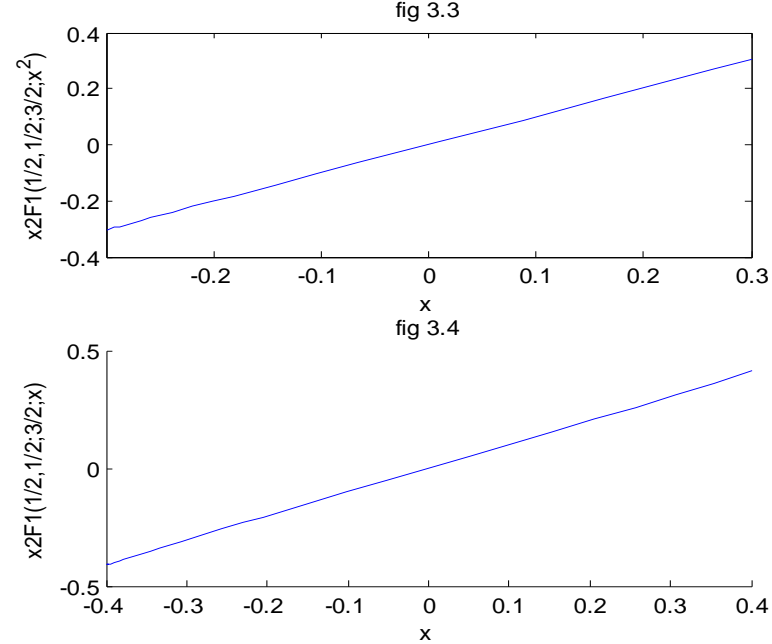

fig 3.5)
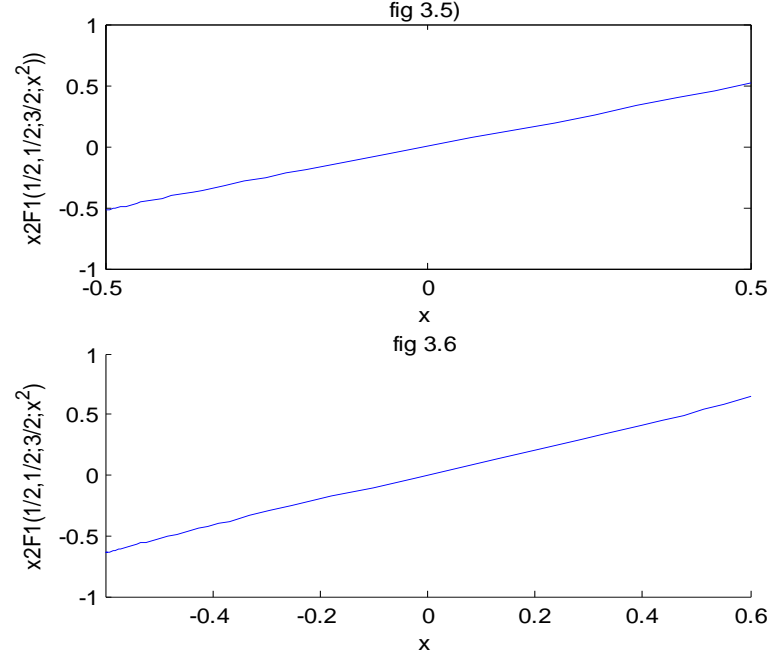

fig 3.7
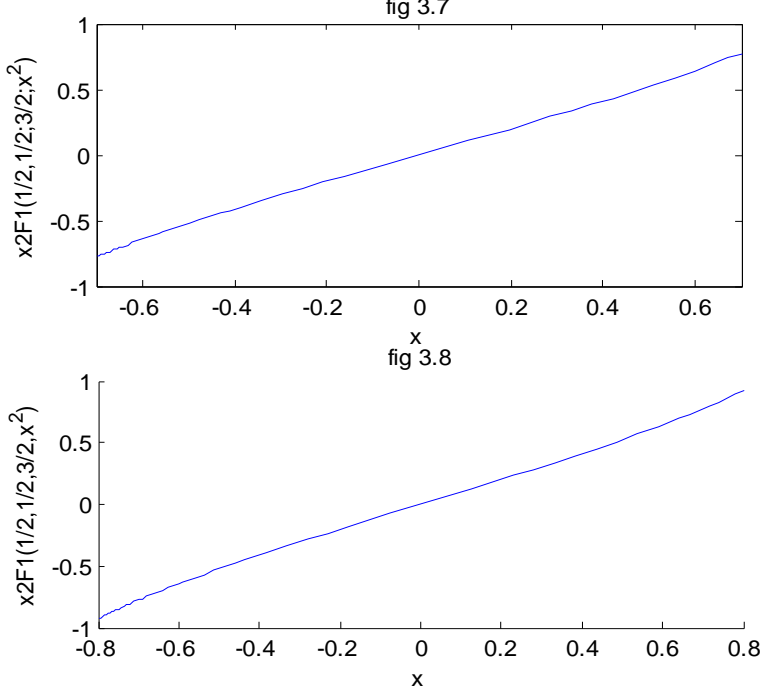

fig 3.9
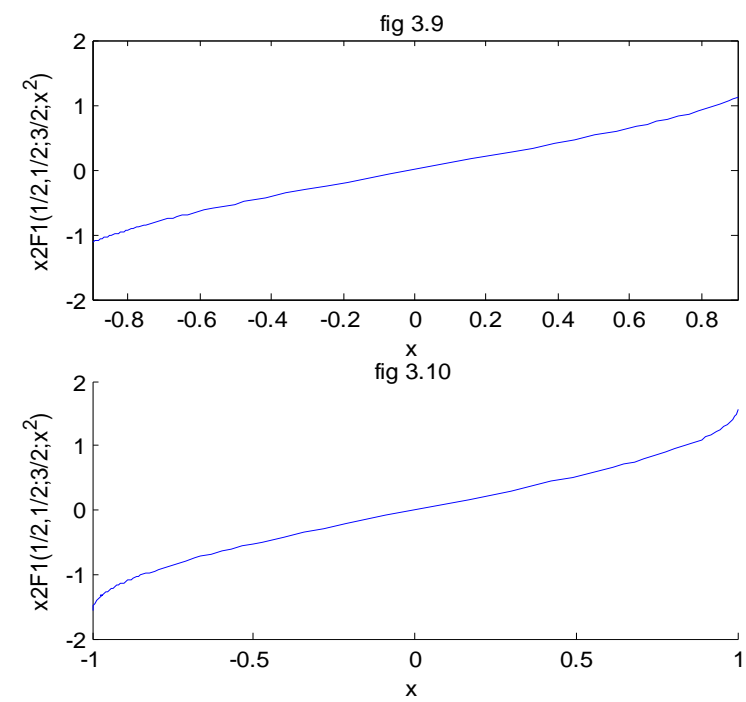

fig 3.11
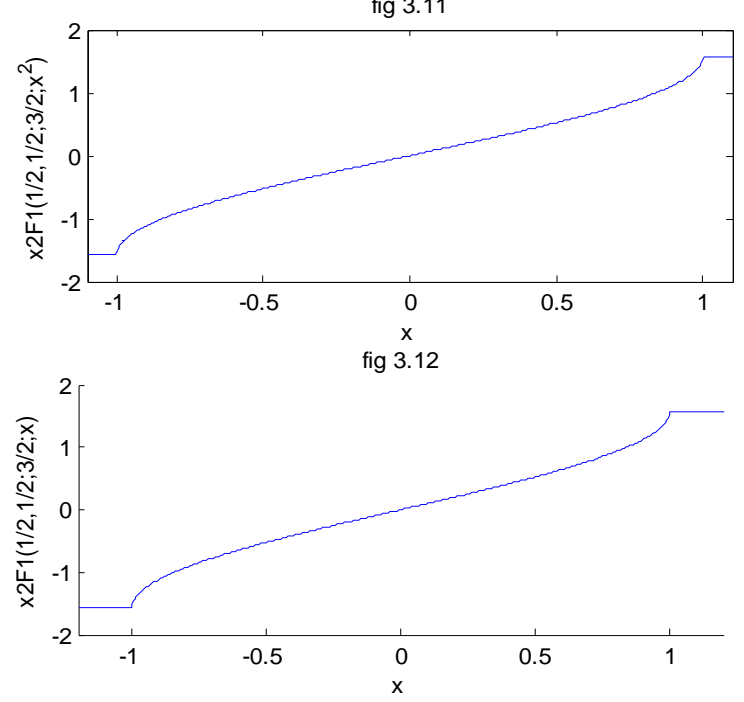

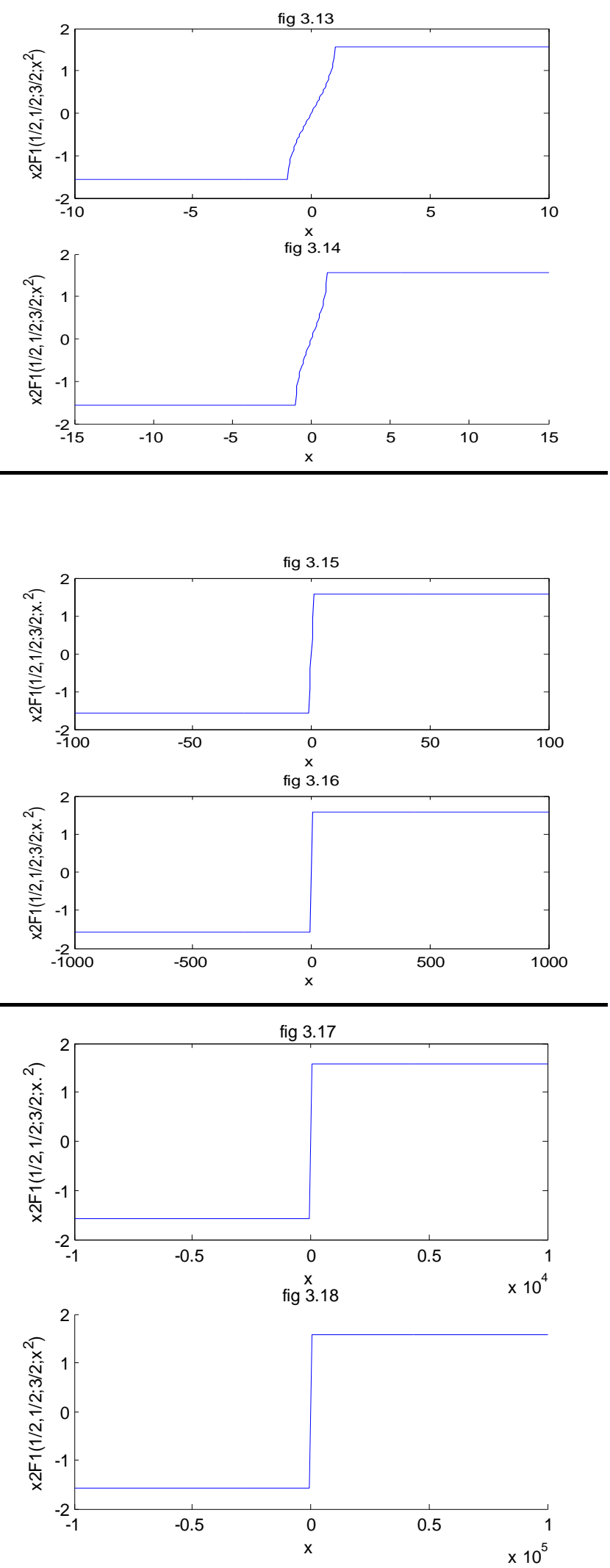

\section{Interpretation of Trends $x_{2} F_{1}(1 / 2,1 / 2 ; 3 / 2$; $\left.\mathbf{x}^{2}\right)$}

When we study the nature of a hypergeometric function $\mathrm{x} 2 \mathrm{~F} 1$ $(1 / 2,1 / 2 ; 3 / 2 ; \mathrm{x} 2)$ in different rages of $\mathrm{x}$, as depicted in fig 3.13.18 ,we observe that the graph between $\mathrm{x} 2 \mathrm{~F} 1(1 / 2,1 / 2 ; 3 / 2 ; \mathrm{x} 2)$ and $x$ from fig 3.1 to fig 3.6, in the range of $x$ from [-0.1:0.1] to [0.6:0.6] remains approximately unchanged. While from fig 3.7 to fig 3.10, in the higher range of $x$ from [-0.7:0.7] to [-1:1]), it can be seen that the graph between $\mathrm{x} 2 \mathrm{~F} 1(1 / 2,1 / 2 ; 3 / 2 ; \mathrm{x} 2)$ and $\mathrm{x}$ shows variation at end points. In the same manner when we increase the range of $x$ from [-1.1:1.1] to [-100:100] from fig 3.8 to fig 3.15 maximum part of the graph between $\mathrm{x} 2 \mathrm{~F} 1(1 / 2,1 / 2$; $3 / 2 ; \mathrm{x} 2$ ) and $\mathrm{x}$ is parallel to $\mathrm{x}$ axis because the hypergeometric function $\mathrm{x} 2 \mathrm{~F} 1(1 / 2,1 / 2 ; 3 / 2 ; \mathrm{x} 2)$ contains some complex number data together with real number data. The parallel line to $x$ axis in the graph shows the real part of the complex number data. When we take higher range of $x$ from [-1000:1000] to [-100000:100000], then from fig 3.16 to fig 3.18, it can be seen that the pattern of the graph between $\mathrm{x} 2 \mathrm{~F} 1(1 / 2,1 / 2 ; 3 / 2 ; \mathrm{x} 2)$ and $\mathrm{x}$ is approximately same. The real part of all complex number data in the database is constant for negative values of $\mathrm{x}$ and near approx 0 for positive values of $\mathrm{x}$.

\section{Comparison of the Trends of Different Generalized Hypergeometric Functions}

Here we have compared the different generalized hypergeometric functions specifically $1 \mathrm{~F} 1(-1 ; 1 ; \mathrm{x}), 2 \mathrm{~F} 1(-1,2 ; 1 ; \mathrm{x}), 3 \mathrm{~F} 2(-1,2$, $3 ; 1,2 ; \mathrm{x})$ and $4 \mathrm{~F} 3(-1,2,3,4 ; 1,2,3 ; \mathrm{x})$. In the following figures, blue line represents the function $1 \mathrm{~F} 1(-1 ; 1 ; \mathrm{x})$, green line represents the function $2 \mathrm{~F} 1(-1,2 ; 1 ; \mathrm{x})$, red line represents the function $3 F 2(-1,2,3 ; 1,2 ; x)$ and indigo line represents the function $4 \mathrm{~F} 3(-1,2,3,4 ; 1,2,3 ; \mathrm{x})$. All the above functions follow similar pattern, when we move from the lower hypergeometric function to higher hypergeometric function in the defined range of $\mathrm{x}$, while the values of higher hypergeometric functions increase with the decrease in the value of $x$ and the values of higher hypergeometric function decrease when we increase the value of $x$.

Fig 4

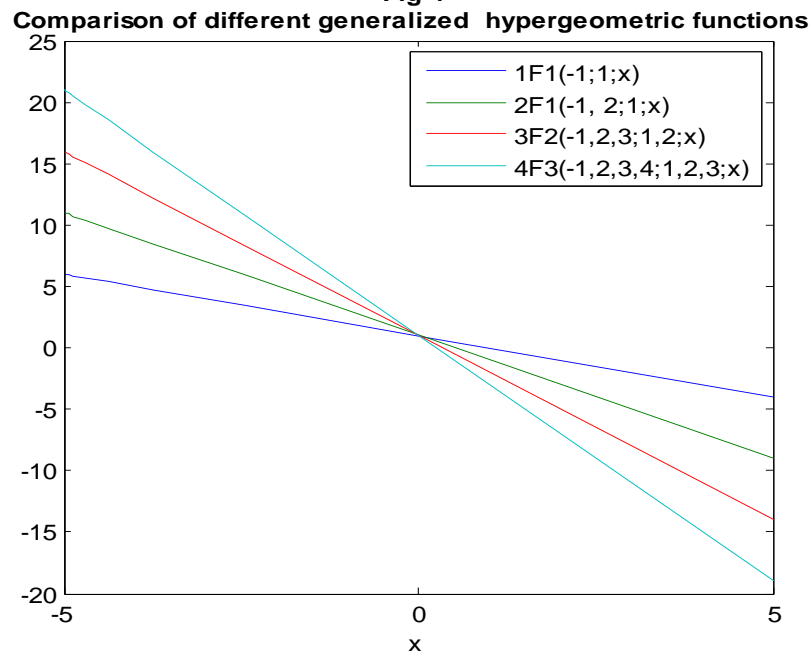




\section{CONCLUSION}

The results discussed in the present paper have enabled us to find the trends of different functions in various ranges and have paved the way for comparison of trends. This type of research work is of immense importance in the disciplines like Biological, Medical and Social Sciences where hypergeometric distributions find applications and can open new vistas of interest for research work on statistical decision theory and applications.

\section{REFERENCES}

[1]. Askey, R. A.; Daalhuis, Adri B. Olde (2010), "Generalized hypergeometric function", in Olver, Frank W. J.; Lozier, Daniel M.; Boisvert, Ronald F. et al., NIST Handbook of Mathematical Functions, Cambridge University Press, ISBN 978-0521192255.

[2]. Bevel, Tom; Gardner, Ross M. (2008) Bloodstain Pattern Analysis With an Introduction to Crimescene Reconstruction, 3rd Ed. CRC Press.

[3]. Daalhuis, Adri B. Olde (2010), "Hypergeometric function", in Olver, Frank W. J.; Lozier, Daniel M.; Boisvert, Ronald F. et al., NIST Handbook of Mathematical Functions, Cambridge University Press. Desmond J. Higham, Nicholas J. Higham (2005), MATLAB guide / SIAM.
[4]. Dwork, B(1990), Generalized Hypergeometric Functions. Oxford, England: Clarendon Press.

[5]. Hui Wang, Saumuy Suriano and Liang Zhou (2009), "highdefinition metrology based spatial variation pattern analysis for machining process monitoring and diagnosis", ASME 2009 International Manufacturing Science and Engineering Conference/ West Lafayette, Indiana (USA)/ Volume 2, ISBN: 978-0-7918-4362-8/ Paper no. MSEC2009-84154 pp.471-480.

[6]. Rumshisky, Anna, and Pustejovsky, James (2006), "Inducing Sense-Discriminating Context Patterns from Sense-Tagged Corpora". LREC, Genoa, Italy.

[7]. Stormy Attaway (2009), "MATLAB: a practical introduction to programming and problem solving"/ Butterworth-Heinemann.

[8]. Watanabe Y. and Takahashi K. (1998), "a fast structural matching and its application to pattern analysis of 2-D electrophoresis images"/ Image Processing, 1998. ICIP 98. Proceedings. International Conference / page(s): $804-808$ vol.3.

[9]. Yoshida, Masaaki (1997). Hypergeometric Functions, My Love: Modular Interpretations of Configuration Spaces. Braunschweig/Wiesbaden: Friedr. Vieweg \& Sohn. MR1453580.ISBN 3-528-06925-2. 